\title{
Response Surface Method for Strength Analysis and Proportion Optimization of New Type Sealing Materials
}

\author{
Sheng Xue $\mathbb{D}^{\text {, }}$, Xin Guo $\mathbb{D}$, Chunshan Zheng, Yaobin Li, and Xiaoliang Zheng \\ Anhui University of Science \& Technology, Huainan 232001, China \\ Correspondence should be addressed to Xin Guo; guoxin190510@163.com
}

Received 19 April 2021; Revised 26 June 2021; Accepted 8 July 2021; Published 2 August 2021

Academic Editor: Basim Abu-Jdayil

Copyright () 2021 Sheng Xue et al. This is an open access article distributed under the Creative Commons Attribution License, which permits unrestricted use, distribution, and reproduction in any medium, provided the original work is properly cited.

\begin{abstract}
The influence of the interaction among water-cement ratio, content of expansion agent, water reducing agent, and retarder on the compressive strength of new sealing material was studied. The Design-Expert software was used to design experiments, establish a quadratic polynomial regression model, draw response surface, and optimize parameters. The microstructure morphology of the sample is explored by a scanning electron microscope (hereinafter referred to as SEM). The research results show that the interaction between the water-cement ratio and expansion agent content is the most crucial factor affecting the compressive strength of the new sealing material. Under the optimal condition of $0.4 \%$ water reducing agent, $0.04 \%$ retarder, 0.8 watercement ratio, and $8 \%$ expansion agent, the compressive strength of the sealing material cured for $3 \mathrm{~d}$ and $7 \mathrm{~d}$ is $39.247 \mathrm{MPa}$ and 41.044 $\mathrm{MPa}$, with the maximum absolute error of $1.71 \%$ and $2.81 \%$, which proves the high accuracy of the model. The main hydration products of the new sealing material are ettringite and C-S-H gel, interlacing each other to form a dense structure, which contributes to the high strength of the new sealing material.
\end{abstract}

\section{Introduction}

China is currently faced with the most severe gas disaster in coal mines in the world [1-3]. Gas predrainage is effective for coal mine gas control, and the performance of sealing material is the key to ensuring drainage efficiency. The coal mine gas drilling sealing material can be divided into inorganic grouting material and organic grouting material. Inorganic sealing materials are mainly cement mortar, low-cost but easy to shrink and crack $[4,5]$. Organic sealing materials, including polyurethane and modified resin [6-8], have a better sealing effect but are expensive, flammable, and toxic [9, 10]. In recent years, scholars have studied composite sealing materials for coal mines. Some researchers have developed a CF expansion sealing material with cement, the base material, and metal $\mathrm{Al}$ powder, gypsum, and other inorganic additives with good expansibility $[11,12]$. Glass fiber would reduce the fluidity of pure cement paste, and the higher the content of glass fiber, the more pronounced the effect [13]. Carbon nanofibers can effectively increase the shrinkage and crack resistance of ultra-fine cement while keeping the hardness unchanged [14]. Fly ash was used as a base material and adding water-retaining agent, expansion agent. This material, with a certain degree of expansion, is not easy to shrink and adheres tightly to coal and could significantly improve the mechanical properties of grouting materials [15-17]. The strength of the sulfoaluminate cement sealing material decreases rapidly with the increase of the watercement ratio [18]. Portland cement has been used to modify the polyurethane material and developed a new grouting material, which not only keeps good mechanical properties of polyurethane material but also overcomes the shortcoming of flammability [19]. Wang et al. [20-22] developed a new polymer sealing material for underwater tunnels and studied its swelling property, mechanical property, flame retardant property, and creep recovery property. Tan et al. [23] studied the waterproof performance of two kinds of water swellable pad materials: water swellable rubber (WSR) and water swellable polyurethane (WSP). Expansion tests were carried out to determine the expansion ratio under 
compression and free expansion conditions. A dynamic mechanics analyzer (DMA) was used to measure the storage modulus under different compression pressures and different saline environments. The morphology of WSR and WSP was observed by scanning electron microscopy (SEM). Liu et al. $[24,25]$ studied the enhancement effect of expansion agent on the performance of underground mass concrete structure. The field test results show that the expansion strain of concrete can be increased effectively by the postcast and postcast expansion reinforcement belts, which indicates that the expansion agent can enhance the crack prevention performance of concrete structures in situ.

With the increase of coal mining depth, the in situ stress increases gradually. Under the action of high in situ stress, the borehole sealing section is easy to cause hole collapse, resulting in air leakage, which is not conducive to gas extraction. In order to improve the gas extraction efficiency, the compressive strength of grouting materials was studied. This paper investigates the performance of composite sealing materials from the perspective of macromechanics and microstructure with the quadratic polynomial regression model. The results reveal that the interaction between the water-cement ratio, retarder, expansion agent, and water reducing agent in the composite sealing material system significantly affects the compressive strength of the sealing material cured for $3 \mathrm{~d}$ and $7 \mathrm{~d}$. The optimal ratio is determined by the verification test, and the mechanism of action of the new sealing material is revealed by SEM analysis.

\section{Materials and Methods}

2.1. Experimental Materials. The base material used in the experiment is ultrafine Portland cement. The measured values of D90 and D50 are $12.6 \mu \mathrm{m}$ and $5 \mu \mathrm{m}$, respectively, which can be effectively injected into microcracks below $0.1 \mathrm{~mm}$. The seaweed powder with a white appearance, which is easily soluble in water, is used as the retarder. The solution is a colorless and transparent viscous liquid, which can advance the setting time and improve the strength of cement materials [26]. After being added, PCE (polycarboxylic acid water-reducing agent), a white powder, which is easily soluble in water, can disperse cement particles with the waterreduction rate of $20-35 \%$ [27, 28]. The compound expansive agent of calcium oxide and calcium sulfate (HCSA), with a gray-white appearance, promotes a good spatial structure of cement hydration products [29, 30]. The composition of ultrafine cement and expansion agent used in the experiment is shown in Table 1.

2.2. Experimental method. 29 groups of experiments with four factors and three levels were designed using BoxBehnken experiment design function in Design-Expert 8.0.5 software. The steps of the parameter optimization process are shown in Figure 1. The four factors are water-cement ratio, retarder content, water reducing agent content, and expansion agent content, as shown in Table 2. The materials were mixed, then water was added, and the mixture was poured into the triple mold $(7.07 \mathrm{~cm} \times 7.07 \mathrm{~cm} \times 7.07 \mathrm{~cm})$.
The mold surface was scraped flat and put into the curing box. After curing the mixture for one day, the mold was removed, and then, the stone body was cured for $3 \mathrm{~d}$ and $7 \mathrm{~d}$.

The compressive strength of stones of different ages was tested by the RMT uniaxial press, as shown in Figure 2. The microstructure of the new sealing material and ordinary cement materials was then observed by the FEI Quanta 200 FEG environmental scanning electron microscope. After the experiment, the response surface regression analysis was carried out by Design-Expert 8.0.5 software. By taking compressive strength as the response value, a quantitative regression model of the relationship between the compound dosing amounts of admixtures was obtained [31], which provides a basis for optimizing the sealing material.

\section{Experimental Results}

It can be seen from Table 3 that after $3 \mathrm{~d}$ curing (temperature $20 \pm 2^{\circ} \mathrm{C}$, relative humidity above $95 \%$ ), the minimum compressive strength of the new sealing material is $23.997 \mathrm{MPa}$, and the maximum is $39.918 \mathrm{MPa}$. After $7 \mathrm{~d}$ curing (the curing conditions are the same), the minimum compressive strength is $27.012 \mathrm{MPa}$ and the maximum is $42.197 \mathrm{MPa}$. These results show that the new sealing material has good mechanical properties.

\section{Response Surface Optimization Analysis}

According to the experimental results in Table 3, the watercement ratio, retarder, water reducing agent, and expansion agent were set as independent variables $A, B, C$, and $D$, and the compressive strength of the samples cured for $3 \mathrm{~d}$ and $7 \mathrm{~d}$ was used as the objective function for multiple nonlinear regression fitting.

4.1. Model Variance Analysis and Significance Test. As shown in Table 4, the $P$ values of the two models are both less than 0.0001 , indicating a small experimental error [32]. It can be seen from the significance test that the significance order of each factor in the regression equation of the sample cured for $3 \mathrm{~d}$ is as follows: $A$ (water-cement ratio) $>D$ (expansion agent $)>C$ (water reducing agent $)>B$ (retarder $)$; interaction of different factors: $A D$ (water-cement ratio, expansion agent) $>A C$ (water-cement ratio, water-reducing agent) $>A B$ (water -cement ratio, retarder) $>C D$ (water-cement ratio, expansion agent $)>B D$ (retarder, expansion agent $)>B C$ (retarder, water reducing agent). The $P$ value of $A$ and $D$ is less than 0.0001 , indicating extremely significant influence. The $P$ value of $B$ and $C$ is greater than 0.05 , showing the insignificant impact. The $P$ value of $A D$ and $A C$ is less than 0.05 , suggesting a significant effect. The $P$ value of $A B, B C, B D$, and $C D$ is greater than 0.05 , indicating insignificant influence. The $P$ value of the $B C$ is 0.8102 , meaning the least significant impact. According to the compressive strength of the experimental scheme, a polynomial regression equation of the compressive strength $\left(R_{3 \mathrm{~d}}\right.$, $R_{7 \mathrm{~d}}$ ) of the independent variables $A, B, C$, and $D$ can be obtained as 
TABLE 1: Chemical composition of raw materials (\%).

\begin{tabular}{|c|c|c|c|c|c|c|c|c|}
\hline Chemical composition & $w\left(\mathrm{SiO}_{2}\right)$ & $w\left(\mathrm{Al}_{2} \mathrm{O}_{3}\right)$ & $w\left(\mathrm{Fe}_{2} \mathrm{O}_{3}\right)$ & $w(\mathrm{CaO})$ & $w(\mathrm{MgO})$ & $w\left(\mathrm{SO}_{3}\right)$ & Loss & Total \\
\hline HCSA expanding agent & 4.96 & 8.52 & 0.99 & 64.18 & 2.67 & 16.97 & 1.19 & 99.48 \\
\hline Superfine Portland cement & 20.57 & 9.89 & 3.08 & 57.65 & 2 & 2.7 & 2.6 & 98.49 \\
\hline
\end{tabular}

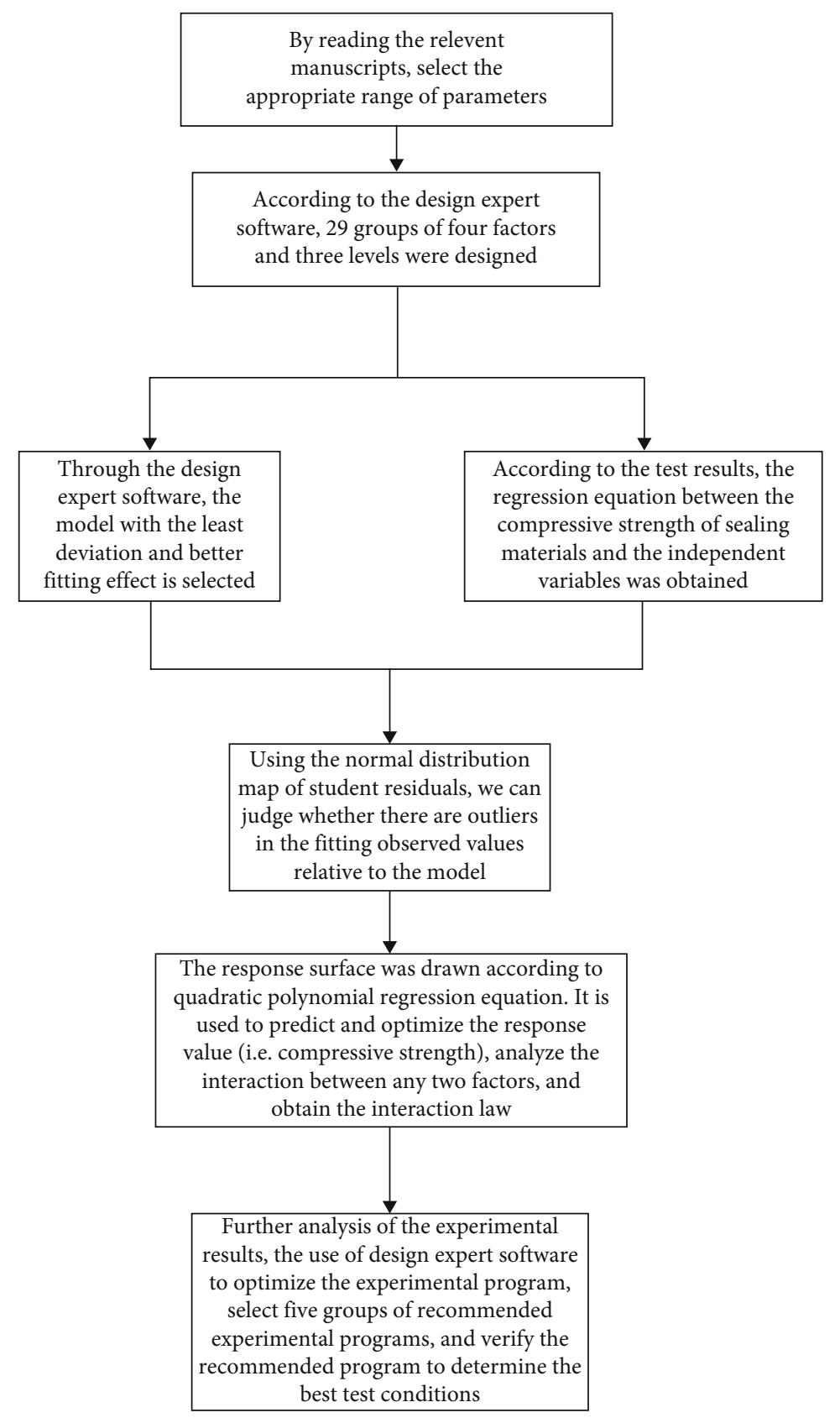

FIGURE 1: Steps of the parameter optimization process.

TABLE 2: Range of factors in the experiment.

\begin{tabular}{lcccc}
\hline \multirow{2}{*}{ Test group } & \multicolumn{2}{c}{ Value range of each factor (\%) } \\
& Water-cement ratio & Retarder & Water-reducing agent & Expanding agent \\
\hline ZJ1-29 & $0.8 \sim 1.0$ & $0.03 \sim 0.05$ & $0.3 \sim 0.5$ & $8-10$ \\
\hline
\end{tabular}




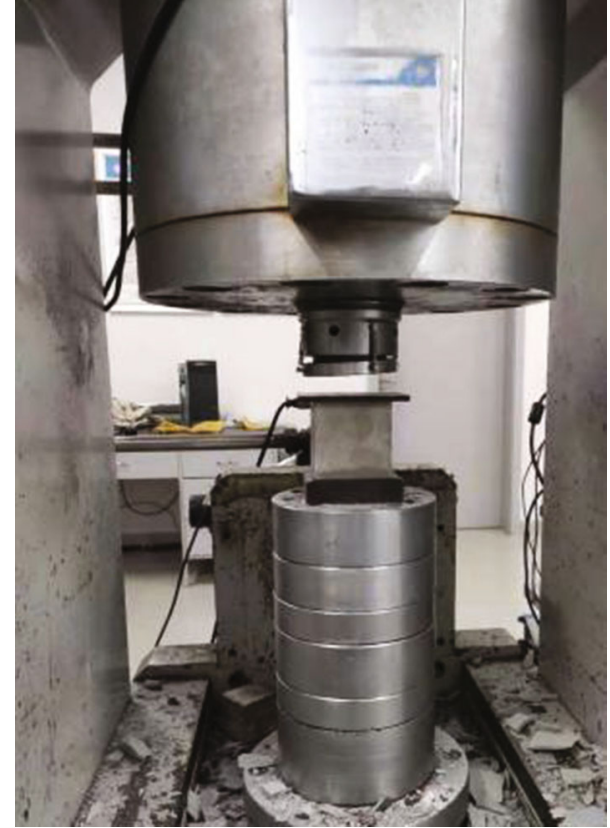

Figure 2: Compressive strength test of composite material specimen.

$$
\begin{aligned}
R_{3 \mathrm{~d}}= & +29.601-3.65 * A-0.47 * B+0.6 * C-1.91 * D \\
& -1.01 * A B-1.10 * A C+1.63 * A D+0.12 * B C \\
& +0.51 * B D-0.54 * C D+0.84 * A^{2}-2.86 * B^{2} \\
& +1.04 * C^{2}+1.61 * D^{2},
\end{aligned}
$$

$$
\begin{aligned}
R_{7 \mathrm{~d}}= & +30.38-3.41 * A-0.70 * B+0.79 * C-2.42 * D \\
& -0.58 * A B-0.62 * A C+1.54 * A D+0.048 * B C \\
& +0.24 * B D-0.25 * C D+1.44 * A^{2}-1.97 * B^{2} \\
& +1.85 * C^{2}+1.85 * D^{2} .
\end{aligned}
$$

The order of the significance of each factor in the regression equation of specimen cured for 7 days is as follows: $A$ (water-cement ratio) $>D$ (expansion agent) $>C$ (water reducing agent) $>B$ (retarder); interaction of different factors: $A D$ (water-cement ratio, expansion agent) $>A C$ ( water-cement ratio, water-reducing agent) $>A B$ (water-cement ratio, retarder $)>C D$ (water-cement ratio, expansion agent $)>$ $B D$ (retarder, expansion agent $)>B C$ (retarder, water reducing agent). The $P$ value of $A$ and $D$ is less than 0.0001 , indicating extremely significant influence. The $P$ value of $B$ and $C$ is greater than 0.05 , indicating an insignificant impact. The $P$ value of $\mathrm{AD}$ is less than 0.05 , indicating significant interac-

\begin{tabular}{|c|c|c|c|c|c|c|}
\hline & & Param & eter value & & & \\
\hline No. & $\begin{array}{c}\text { Water- } \\
\text { cement } \\
\text { ratio }\end{array}$ & Retarder & $\begin{array}{l}\text { Water- } \\
\text { reducing } \\
\text { agent }\end{array}$ & $\begin{array}{c}\text { Expanding } \\
\text { agent }\end{array}$ & $\begin{array}{c}R_{3 \mathrm{~d}} \\
(\mathrm{MPa})\end{array}$ & $\begin{array}{c}R_{7 \mathrm{~d}} \\
(\mathrm{MPa})\end{array}$ \\
\hline 1 & 0.80 & 0.04 & 0.40 & 8.00 & 39.918 & 42.197 \\
\hline 2 & 0.80 & 0.04 & 0.40 & 10.00 & 30.986 & 32.991 \\
\hline 3 & 0.80 & 0.04 & 0.50 & 9.00 & 37.697 & 38.477 \\
\hline 4 & 0.80 & 0.05 & 0.40 & 9.00 & 31.652 & 34.133 \\
\hline 5 & 0.80 & 0.04 & 0.30 & 9.00 & 33.997 & 35.010 \\
\hline 6 & 0.80 & 0.03 & 0.40 & 9.00 & 29.899 & 32.069 \\
\hline 7 & 0.90 & 0.03 & 0.40 & 10.00 & 26.943 & 28.511 \\
\hline 8 & 0.90 & 0.03 & 0.30 & 9.00 & 27.696 & 31.233 \\
\hline 9 & 0.90 & 0.03 & 0.40 & 8.00 & 30.931 & 32.871 \\
\hline 10 & 0.90 & 0.03 & 0.50 & 9.00 & 28.479 & 32.141 \\
\hline 11 & 0.90 & 0.04 & 0.40 & 9.00 & 29.601 & 30.381 \\
\hline 12 & 0.90 & 0.04 & 0.30 & 10.00 & 31.239 & 32.011 \\
\hline 13 & 0.90 & 0.04 & 0.40 & 9.00 & 29.601 & 30.381 \\
\hline 14 & 0.90 & 0.04 & 0.40 & 9.00 & 29.601 & 30.381 \\
\hline 15 & 0.90 & 0.04 & 0.30 & 8.00 & 32.986 & 36.021 \\
\hline 16 & 0.90 & 0.04 & 0.40 & 9.00 & 29.601 & 30.381 \\
\hline 17 & 0.90 & 0.04 & 0.50 & 8.00 & 35.112 & 38.021 \\
\hline 18 & 0.90 & 0.04 & 0.50 & 10.00 & 31.213 & 32.997 \\
\hline 19 & 0.90 & 0.04 & 0.40 & 9.00 & 29.601 & 30.381 \\
\hline 20 & 0.90 & 0.05 & 0.50 & 9.00 & 27.162 & 29.133 \\
\hline 21 & 0.90 & 0.05 & 0.40 & 8.00 & 28.922 & 30.410 \\
\hline 22 & 0.90 & 0.05 & 0.40 & 10.00 & 26.993 & 27.012 \\
\hline 23 & 0.90 & 0.05 & 0.30 & 9.00 & 25.896 & 28.033 \\
\hline 24 & 1.00 & 0.04 & 0.40 & 8.00 & 28.911 & 31.036 \\
\hline 25 & 1.00 & 0.04 & 0.50 & 9.00 & 26.976 & 29.989 \\
\hline 26 & 1.00 & 0.04 & 0.40 & 10.00 & 26.513 & 27.978 \\
\hline 27 & 1.00 & 0.03 & 0.40 & 9.00 & 26.295 & 28.091 \\
\hline 28 & 1.00 & 0.05 & 0.40 & 9.00 & 23.997 & 27.843 \\
\hline 29 & 1.00 & 0.04 & 0.30 & 9.00 & 27.664 & 29.008 \\
\hline
\end{tabular}
tion. The $P$ value of the $A C$ changes from 0.0432 to 0.3482 , suggesting that the interaction between $A$ and $C$ has a more significant impact on the sample cured for three days, and the longer the sample is cured, the less significant the effect. The $P$ value of $B C$ is 0.9413 , indicating the least significant interaction effect.
TABLE 3: Response surface test design and test results.

As the items ( $F$ value, $R^{2}$ ) of conformity degree comparison were relatively abstract, it was necessary to verify the selected model in other ways. The studentized residual was used to compare the predicted residual value and the actual value (Figure 3 ). The points were mostly concentrated in the center of the map in terms of the abscissas and were distributed approximately on a straight line, indicating that the model was reliable.

4.2. Response Surface Analysis. Figure 4 is the threedimensional surface obtained according to the response value under the interaction of each two independent variables, where the $X$-axis and the $Y$-axis show the factor level and $Z$ -axis shows the compressive strength. The interaction and law of the other two factors under the condition that any two of the four factors $A$ (water-cement ratio), $B$ (retarder content), $C$ (water-reducing agent content), and $D$ (expansion agent content) remain unchanged were determined. 
TABLE 4: Response surface secondary model and ANOVA results.

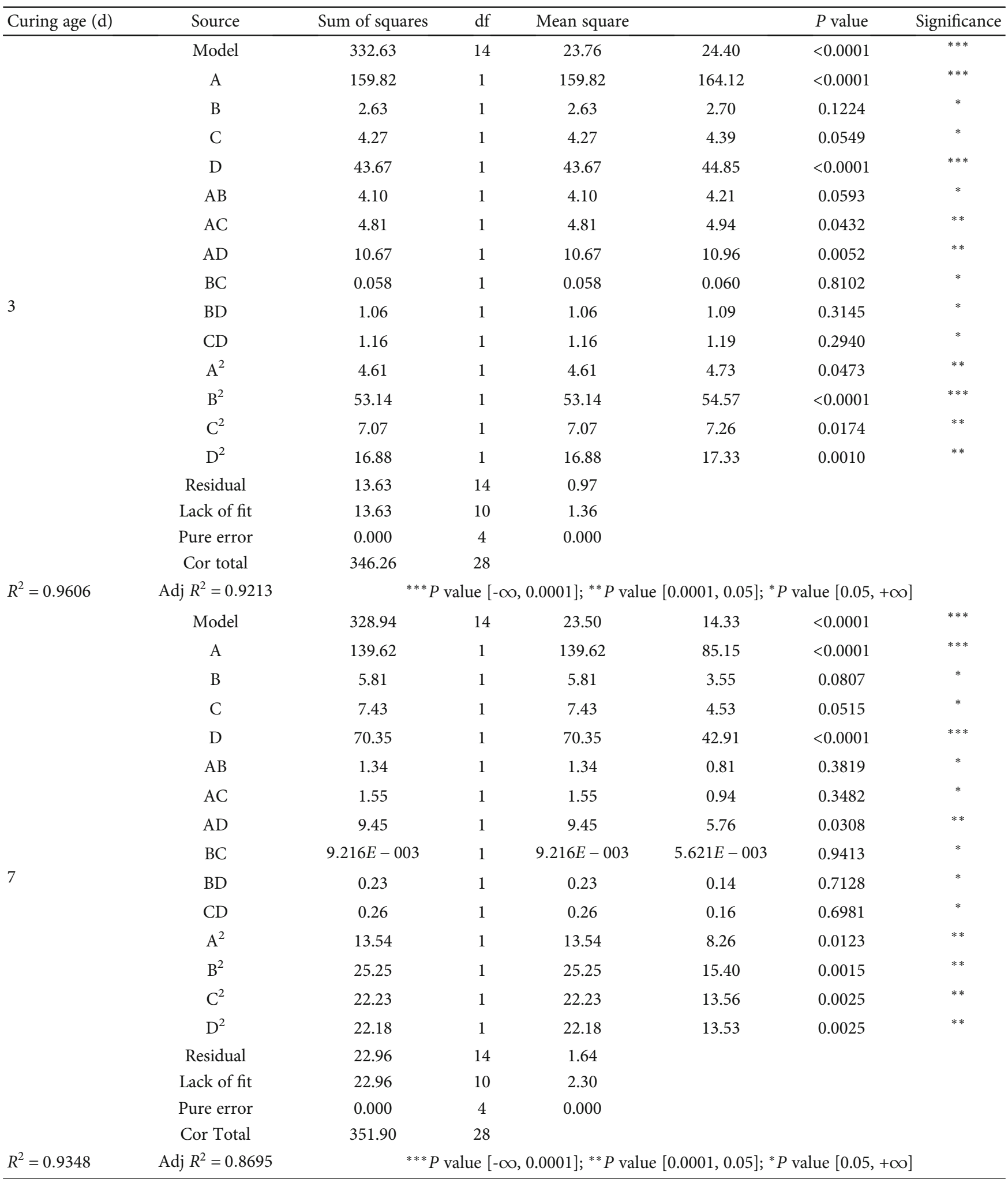

Figures 4(a) and 4(b) show the influence of the interaction between water-cement ratio and expansion agent on the compressive strength of the sample. The compressive strength of the sample varies greatly with the water-cement ratio or the value of the expansion agent. At this time, the response surface is steep, which indicates that the interaction of water-cement ratio and expansion agent has a significant influence on the response value. It is consistent with the 

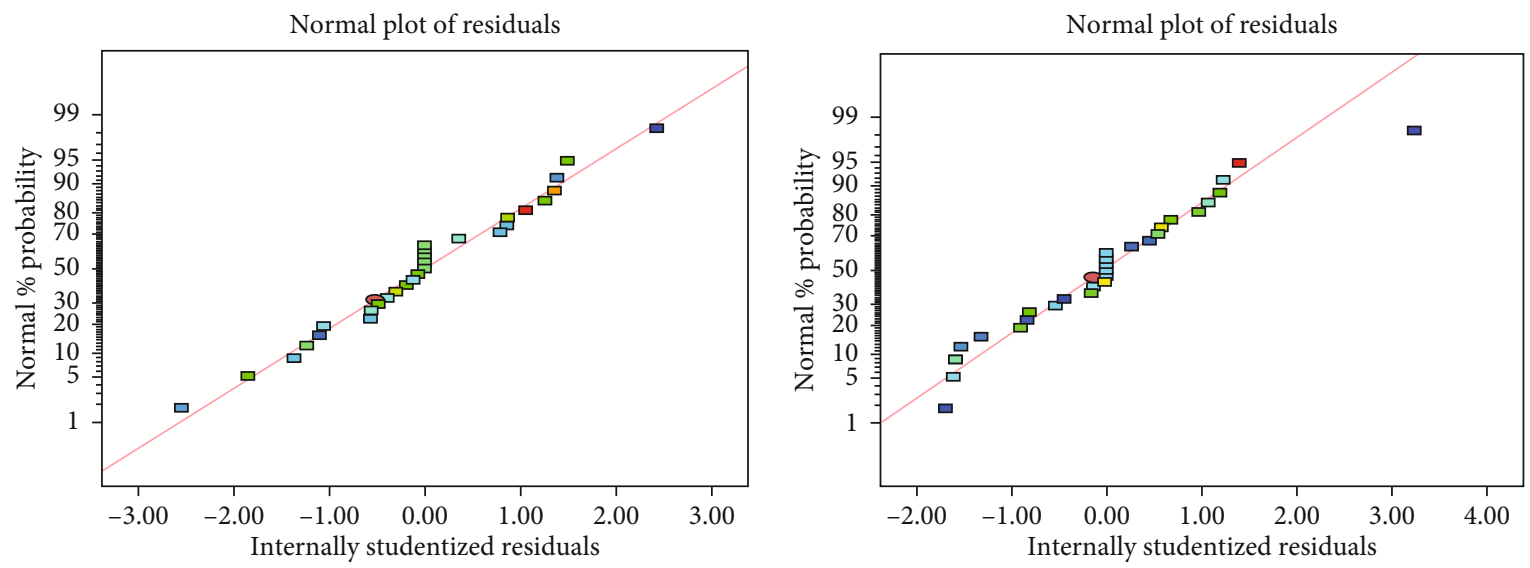

Figure 3: Studentized residual distribution.

results of the previous analysis of variance. When the watercement ratio is low, the compressive strength of the sample increases rapidly with the increase of the expansion agent content. When the water-cement ratio increases to above 0.9 , the compressive strength of the sample increases slowly with the increase of the expansion agent content. When the content of expansion agent is low, the compressive strength of the sample increases rapidly as the water-cement ratio decreases. When the content of expansion agent increases to more than $9 \%$, the compressive strength of the sample increases slowly with the decrease of water-cement ratio.

Figures 4(c) and 4(d) show the influence of the interaction between water-cement ratio and water reducing agent on the compressive strength of the sample. The compressive strength of the sample has a steeper change trend, indicating that the interaction between the water-cement ratio and the water reducing agent has a significant impact on the response value.

The smoother response surface in Figures 4(e) and 4(f) indicates less significant influence of the interaction of the retarder and water-cement ratio on the compressive strength. When the water-cement ratio remains unchanged, the compressive strength of the sample increases first and then decreases with the increase of retarder content. When the content of the retarder is constant, the compressive strength of the sample increases rapidly with the decrease of the water-cement ratio, and the steep response surface shows that the retarder has little effect on the compressive strength.

As shown in Figures 4(g) and 4(h), when the content of the expansion agent is constant, the compressive strength increases with the increase of the water reducing agent, indicating that the expansion agent has less influence on the fluidity. When the value of the water reducing agent reaches the upper limit and the value of the expansion agent reaches the lower limit, the response surface is steep, indicating that the interaction of the two factors has the greatest impact on the compressive strength.

Figures 4(i) and 4(j) show the influence of the interaction between the retarder and expansive agent on the compressive strength of the sample. The change rule of the graph is consistent with the influence rule of the two-factor ANOVA on the response value in Table 4 . When the content of the expansion agent remains constant, the compressive strength increases and then decreases with the increase of the content of the retarder. When the content of the retarder remains unchanged, the compressive strength of the sample decreases rapidly with the increase of the content of the expansion agent, indicating that the effect of the water-cement ratio on the response value is more significant than that of the retarder. The response surface is relatively flat on the whole, indicating that the influence of the interaction between the retarder and the expansive agent is small.

As shown in Figures $4(\mathrm{k})$ and $4(\mathrm{l})$, when the retarder interacts with the expansion agent, the response surface is relatively smooth, indicating that the influence of the interaction on the compressive strength is the least significant, which is consistent with the results of the variance analysis.

4.3. Response Surface Optimization Prediction and Verification. The experimental results were further analyzed by taking the compressive strength of the sample as the optimization index. The optimized experimental scheme was obtained by the Design-Expert software where the content of water reducing agent is $0.4 \%$, the content of retarder is $0.04 \%$, the water-cement ratio is 0.8 , and the content of expansion agent is $8 \%$. The scheme was then verified. Due to limited space, the results were shown in Table 5 without being described in detail. It can be seen that the compressive strength of the specimen cured for $3 \mathrm{~d}$ and $7 \mathrm{~d}$ under the optimal condition are $39.247 \mathrm{MPa}$ and $41.044 \mathrm{MPa}$, with the maximum absolute error between the predicted value and actual value of compressive strength as $2.55 \%$ and $1.77 \%$. Figures 5(a) and 5(b) shows that the measured and predicted values have a high degree of fitting, and the fitting coefficients are 0.9586 and 0.9298 , respectively, indicating that the model is relatively reliable.

\section{Microscopic Characterization of Sealing Material}

It can be seen from Figures 6(a) and 6(b) that the connection between the hydration products of the ordinary cement 


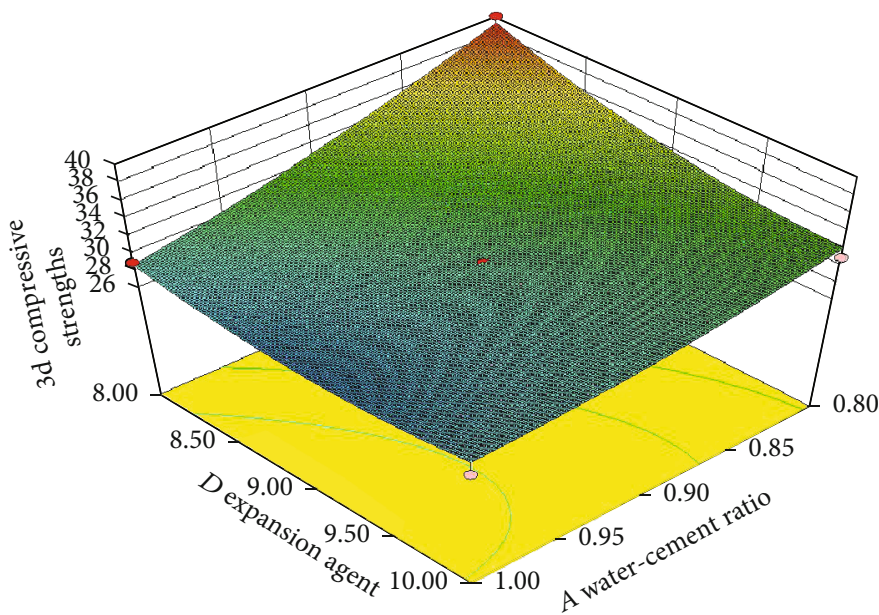

(a)

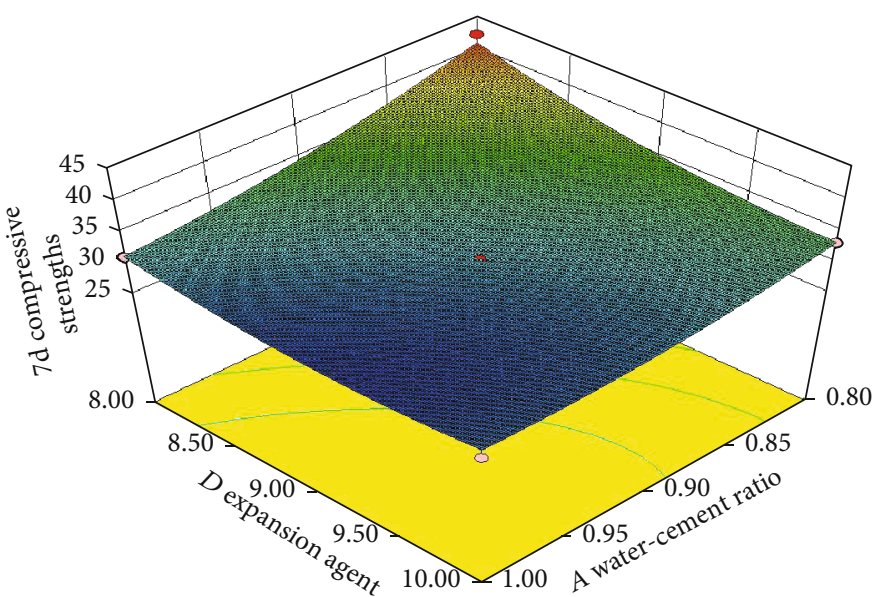

(b)

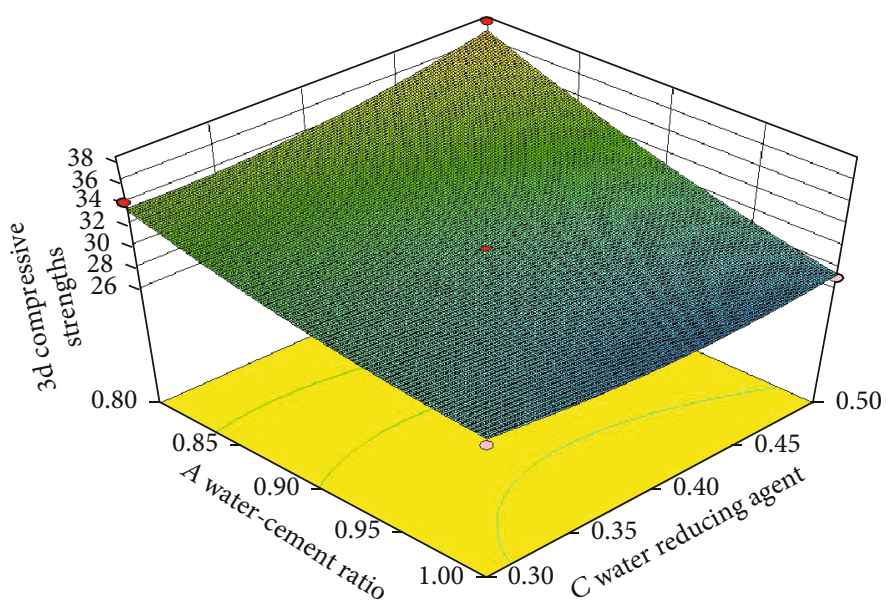

(c)

Figure 4: Continued. 


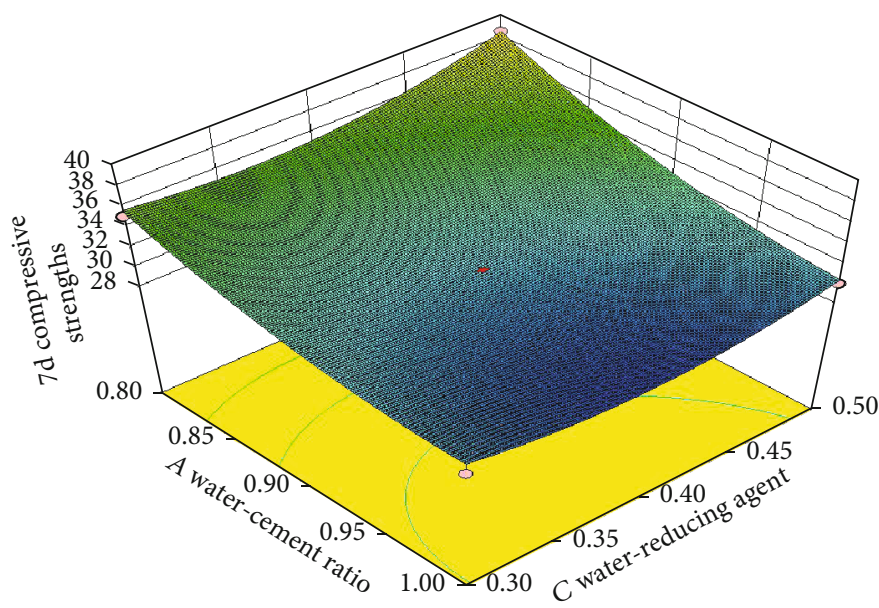

(d)

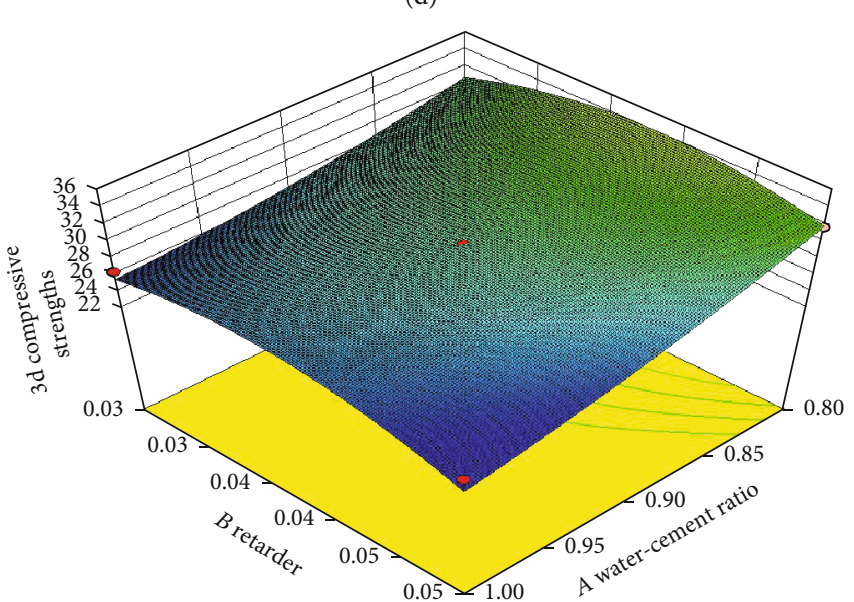

(e)

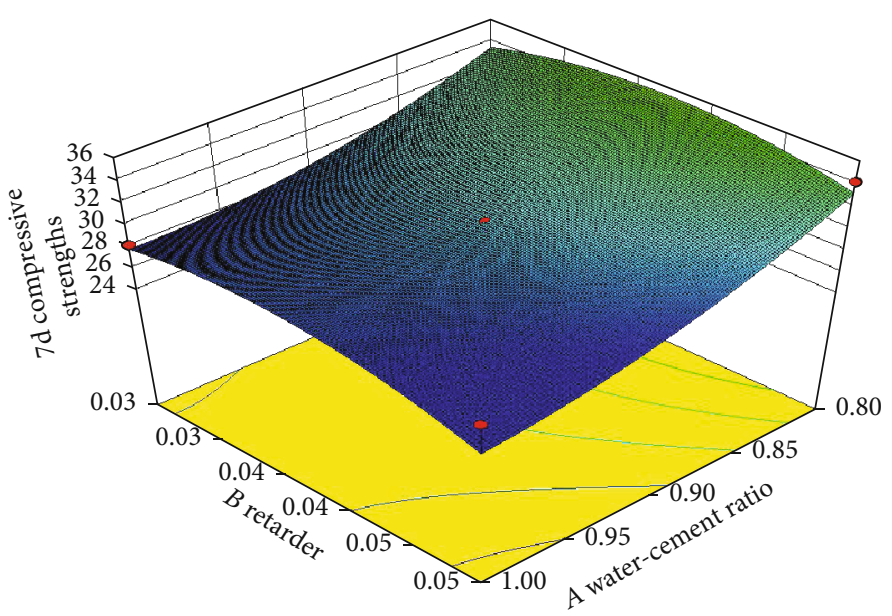

(f)

Figure 4: Continued. 


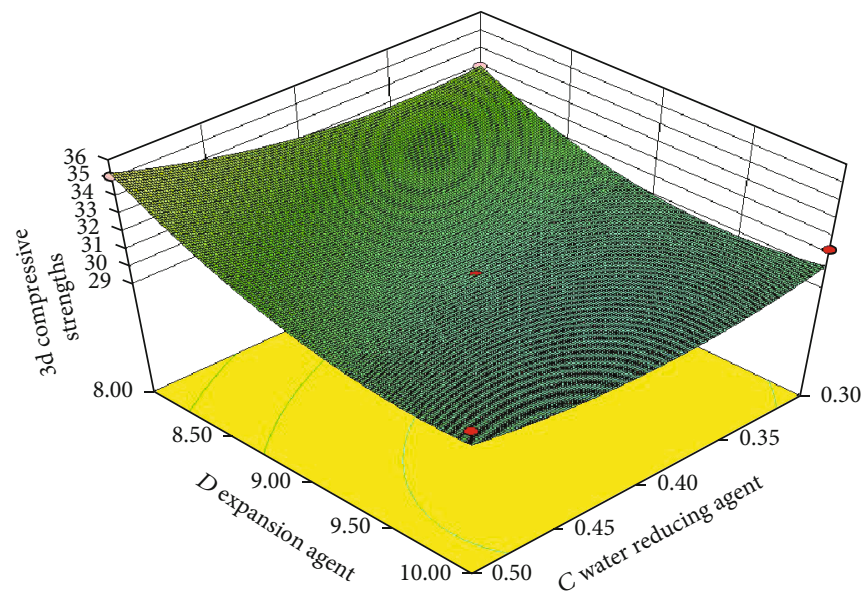

(g)

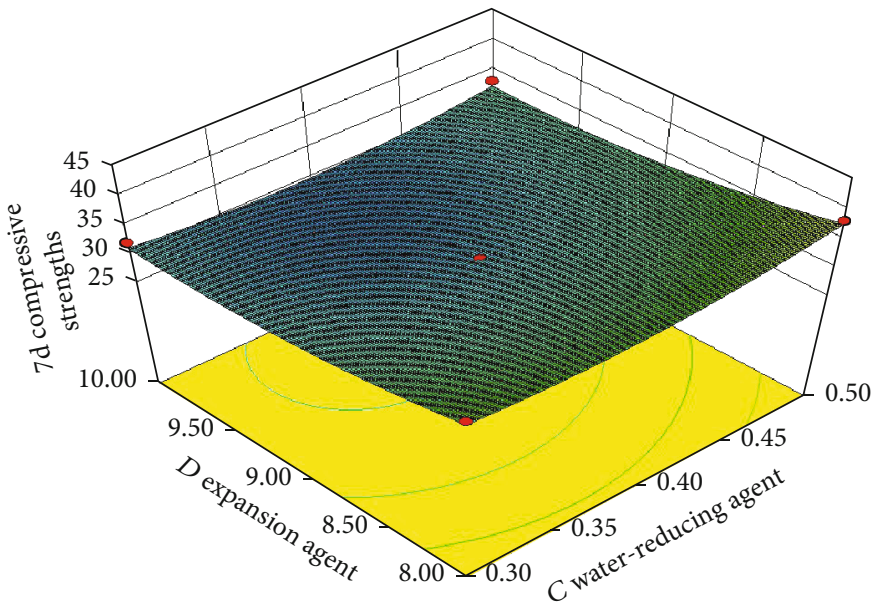

(h)

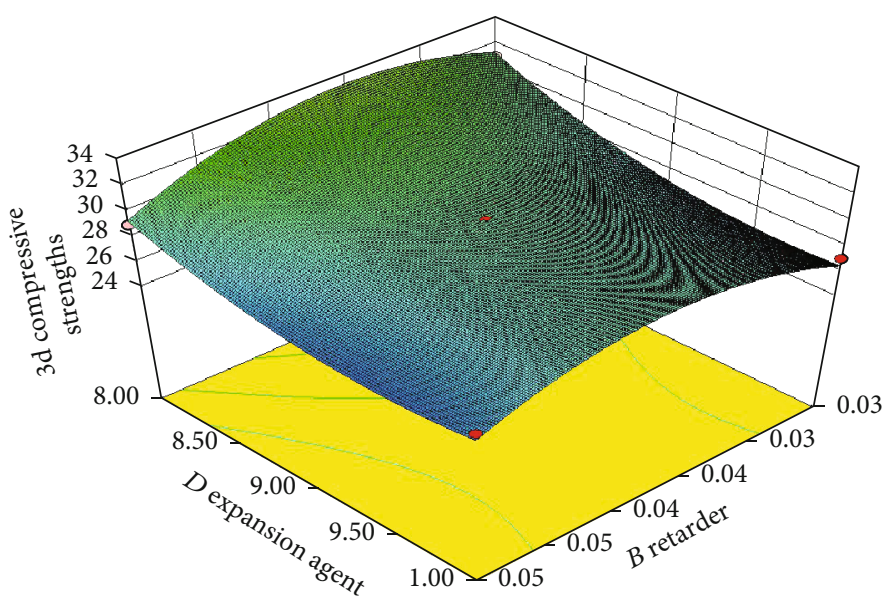

(i)

FIgUre 4: Continued. 


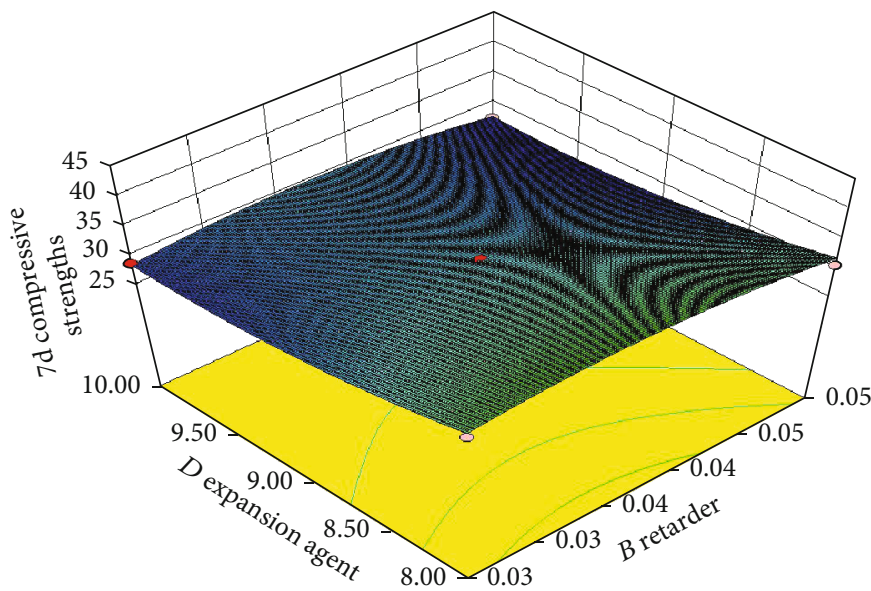

(j)

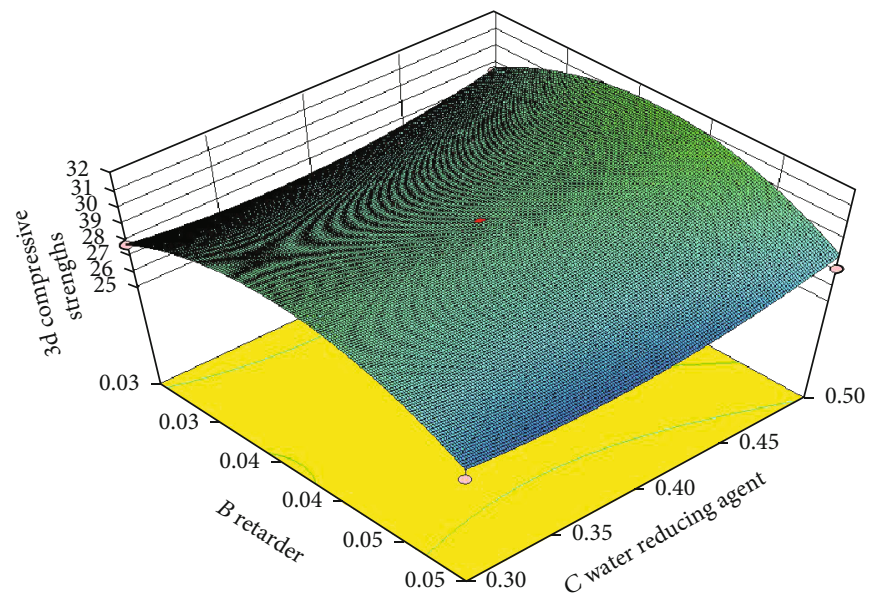

(k)

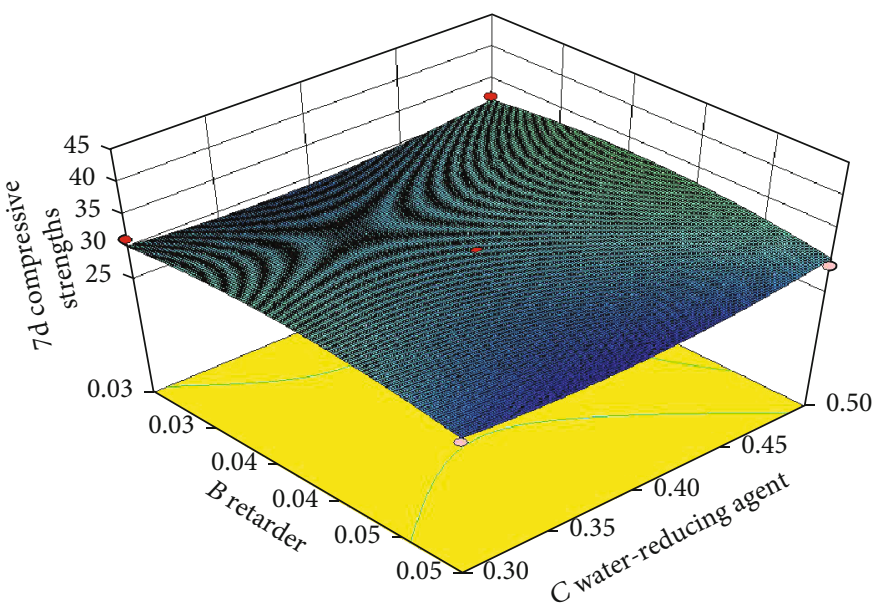

(1)

FIGURE 4: Three-dimensional response curve of compressive strength.

material during curing is loose, resulting in a lower compressive strength. When cured for three days, the cement clinker is encapsulated by C-S-H gel with an obvious pore structure and large pore volume. After 7-day curing, the surface area of the $\mathrm{C}-\mathrm{S}-\mathrm{H}$ gel gradually increases, the volume gradually expands, and the pore becomes smaller. With the hydration reaction, the number of C-S-H gels increases, and some needle-shaped AFt crystals appear.

It can be seen from Figures 6(c) and 6(d) that the gel particles of the new sealing material are interconnected 
TABLe 5: Optimum Scheme and Results.

\begin{tabular}{|c|c|c|c|c|c|c|}
\hline No. & $\begin{array}{c}3 \mathrm{~d} \text { compressive strength } \\
\text { (actual) }(\mathrm{MPa})\end{array}$ & $\begin{array}{l}3 \mathrm{~d} \text { compressive strength } \\
\text { (prediction) }(\mathrm{MPa})\end{array}$ & $\begin{array}{c}\text { Error } \\
(\%)\end{array}$ & $\begin{array}{c}7 \mathrm{~d} \text { compressive strength } \\
\text { (actual) }(\mathrm{MPa})\end{array}$ & $\begin{array}{l}7 \mathrm{~d} \text { compressive strength } \\
\text { (prediction) }(\mathrm{MPa})\end{array}$ & $\begin{array}{c}\text { Error } \\
(\%)\end{array}$ \\
\hline 1 & 32.918 & 32.099 & 2.55 & 33.197 & 33.378 & -0.54 \\
\hline 2 & 33.554 & 33.031 & 1.58 & 36.031 & 35.463 & 1.61 \\
\hline 3 & 31.487 & 31.243 & 0.78 & 33.717 & 33.615 & 0.30 \\
\hline 4 & 26.601 & 26.490 & 0.42 & 27.449 & 27.381 & 0.25 \\
\hline 5 & 28.587 & 28.032 & 1.98 & 30.936 & 30.398 & 1.77 \\
\hline
\end{tabular}

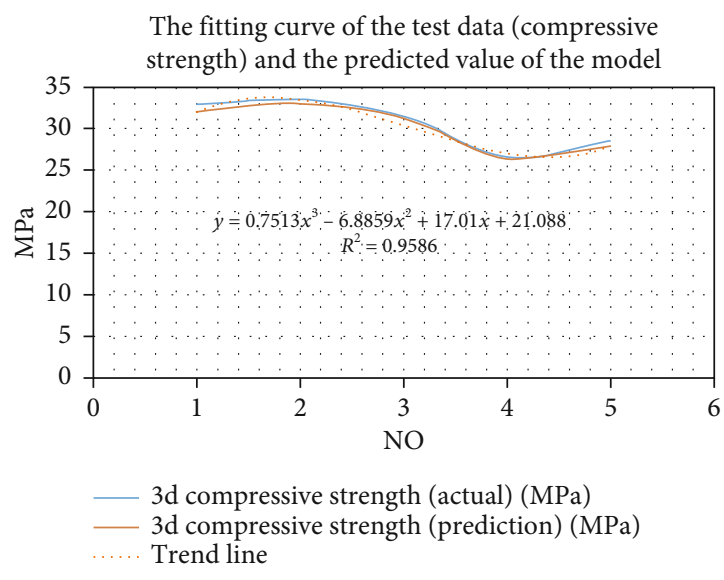

(a)

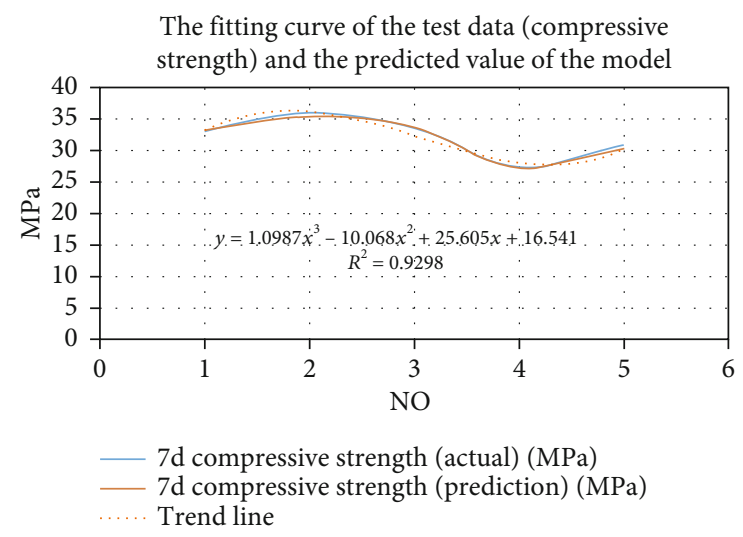

(b)

FIGURE 5: The fitting curve of the test data (compressive strength) and the predicted value of the model.

compactly, which increases the strength of the material. After $3 \mathrm{~d}$ curing, C-S-H gel with a dense structure and fewer pores was formed, which were wrapped with cement clinker; After $7 \mathrm{~d}$ curing, a large number of ettringite crystals were formed, indicating that the admixture can promote cement hydration reaction, and AFt crystals were generated with an expansion effect. The C-S-H gel and AFt were densely and uniformly cross-bonded together, thereby increasing the strength of the material [33-35].

\section{Conclusions}

(1) The compressive strength of the samples varies greatly with the water-cement ratio or the amount of expansion agent. The compressive strength of the sample increases rapidly with the increase of the content of expansion agent when the water cement is relatively low. When the water-cement ratio increases to more than 0.9 , the compressive strength of the sample increases slowly with the increase of the expansion agent content. When the content of expansion agent is low, the compressive strength of the sample increases rapidly with the decrease of the watercement ratio. When the expansion agent content increases to more than $9 \%$, the compressive strength of the sample increases slowly with the decrease of the water-cement ratio

(2) When the water-cement ratio remains unchanged, the compressive strength of the specimen increases first and then decreases with the increase of the retarder content. When the retarder content is constant, the compressive strength of the sample increases rapidly with the decrease of the watercement ratio

(3) When the content of expansion agent is constant, the compressive strength increases with the increase of the content of water reducer. When the content of expander is constant, the compressive strength increases first and then decreases with the increase of retarder content. When the amount of retarder remains unchanged, the compressive strength of the sample decreases rapidly with the increase of the amount of expansion agent

(4) Through variance analysis and the significance test, the significance order of the influence of each component on the compressive strength were obtained as follows: water cement ratio > expansion agent $>$ water reducing agent $>$ retarder. According to the response surface drawn by the regression equation, the interaction between water-cement ratio and expansion agent has the most significant effect on the compressive strength, and the interaction between retarder and water reducing agent has the least significant effect on the compressive strength

(5) The optimal experimental condition was obtained by response surface analysis: water reducing agent content of $0.4 \%$, retarder content of $0.04 \%$, the 


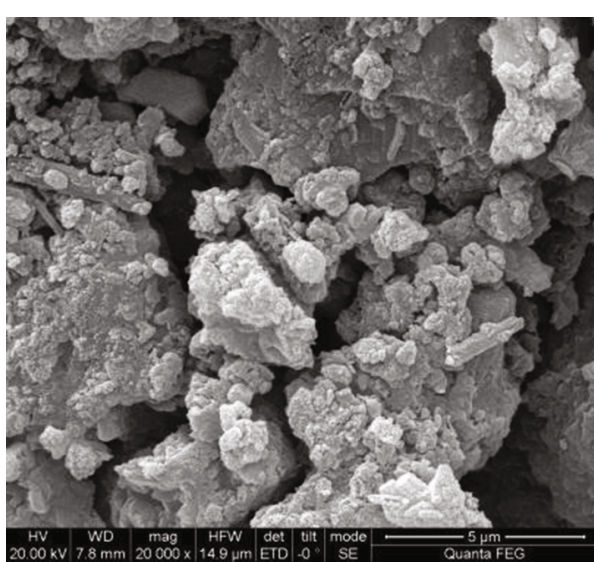

(a) $3 \mathrm{~d}$ curing of ordinary cement

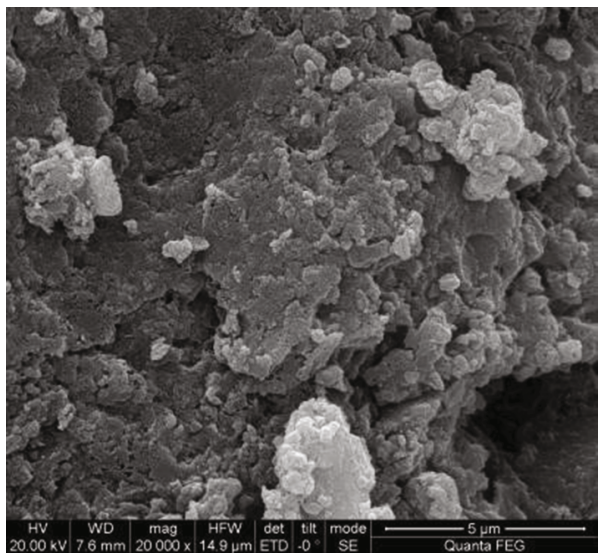

(c) $3 \mathrm{~d}$ curing of new materials

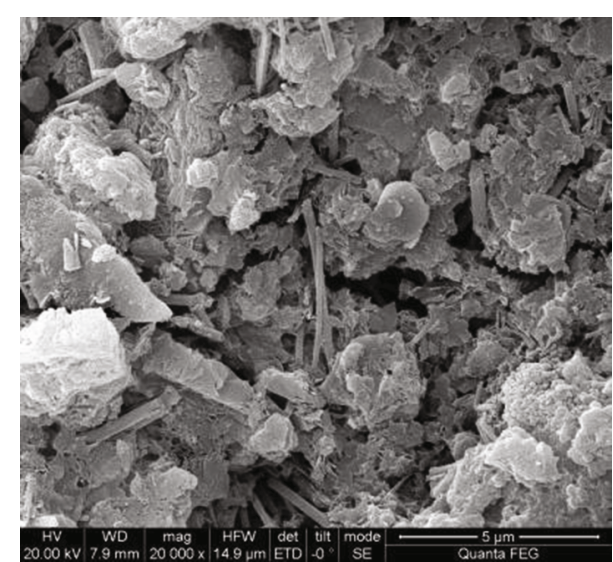

(b) $7 \mathrm{~d}$ curing of ordinary cement

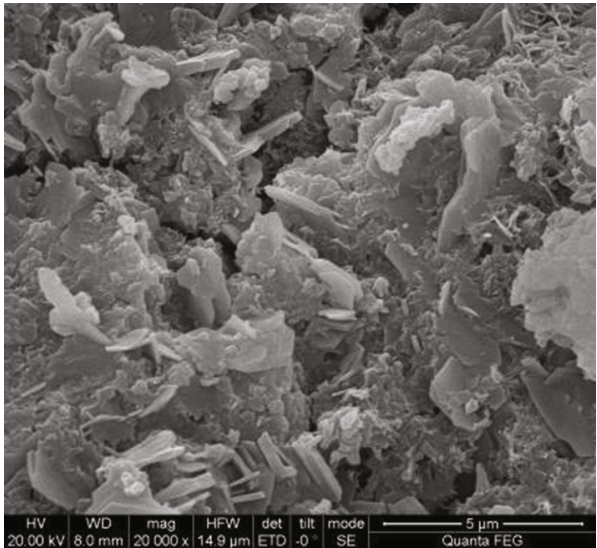

(d) $7 \mathrm{~d}$ curing of new materials

FIGURE 6: SEM micromorphology of hydration products of samples at different ages.

water-cement ratio of 0.8 , and expansion agent content of $8 \%$. The compressive strength of the new sealing material cured for $3 \mathrm{~d}$ and $7 \mathrm{~d}$ was $39.247 \mathrm{MPa}$ and $41.044 \mathrm{MPa}$, with the maximum absolute error of $1.71 \%$ and $2.81 \%$, respectively. The predicted value was highly consistent with the measured value

(6) Compared with ordinary cement materials, the new sealing material has a denser overall structure and fewer pores. The hydration products C-S-H gel, $\mathrm{AFt}$, and other cementing materials, which are uniformly cross-bonded together, increase the uniformity and compactness of the material, thus improving the strength of the material

\section{Data Availability}

The data used to support the findings of this study are available from the corresponding author upon request.

\section{Conflicts of Interest}

The authors declared no potential conflicts of interest with respect to the research, authorship, and/or publication of this article.

\section{Authors' Contributions}

All authors contributed to this paper. Sheng Xue and Xin Guo prepared the manuscript. Chunshan Zheng and Yaobin Li made a substantial contribution to the data analysis. Xiaoliang Zheng participated in the study and reviewed the manuscript.

\section{Acknowledgments}

This research was financially supported by the National Natural Science Foundation of China (Nos. 51934007 and 51904013) and Shandong Key S\&T Innovation Engineering Project (2019JZZY020504).

\section{References}

[1] L. Yuan, "Strategic thinking of simultaneous exploitation of coal and gas in deep mining," Journal of China Coal Society, vol. 41, no. 1, pp. 1-6, 2016.

[2] H. Zhang, Y. Cheng, L. Yuan, L. Wang, and Z. Pan, "Hydraulic flushing in soft coal sublayer: gas extraction enhancement mechanism and field application," Energy Science \& Engineering, vol. 7, no. 5, pp. 1970-1993, 2019.

[3] S. Xue and L. Yuan, "The use of coal cuttings from underground boreholes to determine gas content of coal with direct desorption method," International Journal of Coal Geology, vol. 174, pp. 1-7, 2017. 
[4] Y. Guo, B. L. Zhang, X. G. Zheng, W. Zhou, X. L. Wei, and D. X. Zhu, "Grouting reinforcement technology of superfine cement with wind oxidation zone based on time varying rheological parameters of slurries," Journal of Mining \& Safety Engineering, vol. 36, no. 2, pp. 338-343, 2019.

[5] D. X. Zhu, Y. Guo, W. Wang, G. Guo, and T. An, "Grouting reinforcement technique in wind oxidation zone by power law superfine cement slurry considering the time-varying rheological parameters," Advances in Civil Engineering, vol. 2019, Article ID 2495850, 10 pages, 2019.

[6] X. Gao, Y. Wei, F. M. Wang, and Y. H. Zhong, "Fatigue resistant and microstructure evolution of polyurethane grout materials under uniaxial compression," Acta Materiae Compositae Sinica, vol. 34, no. 4, p. 5507556, 2017.

[7] Y. T. Niu, C. J. Zhang, Z. P. Yang, and X. M. Guan, "Recent progress of organic/inorganic grouting material based on polyurethane," New Chemical Materials, vol. 46, no. 3, pp. 42-44, 2018.

[8] Z. P. Yang, W. J. Zhang, X. M. Guan, and C. J. Zhang, "Preparation, characterization, and properties of silicate/polyurethaneurea composites based on dipropylene glycol dibenzoat," Polymer Composites, vol. 4, no. 5, pp. 507-517, 2016.

[9] X. M. Guan, H. B. Zhang, Z. P. Yang et al., "Research of high performance inorganic-organic composite grouting materials," Journal of China Coal Society, vol. 45, no. 3, pp. 902910, 2020.

[10] W. H. Sui, J. Liu, W. Hu, J. Qi, and K. Zhan, "Experimental investigation on sealing efficiency of chemical grouting in rock fracture with flowing water," Tunnelling and Underground Space Technology, vol. 50, pp. 239-249, 2015.

[11] S. G. Li, J. F. Zhang, C. Zhang, H. F. Lin, and H. J. Yang, "Experimental study on expansion mechanism of new CF sealing material and the key influencing factors," Journal of Mining \& Safety Engineering, vol. 35, no. 2, pp. 415-421, 2018.

[12] T. J. Zhang, R. Y. Bao, S. G. Li, C. Zhang, L. Zhang, and X. K. Jiang, "Experimental study on expansion and creep characteristics of new CF sealing material," Journal of Mining \& Safety Engineering, vol. 36, no. 1, pp. 175-183, 2019.

[13] Q. B. Wang, Q. K. Zhu, T. S. Shao et al., "The rheological test and application research of glass fiber cement slurry based on plugging mechanism of dynamic water grouting," Construction and Building Materials, vol. 189, pp. 119-130, 2018.

[14] J. Hogancamp and Z. Grasley, "The use of microfine cement to enhance the efficacy of carbon nanofibers with respect to drying shrinkage crack resistance of Portland cement mortars," Cement \& Concrete Composites, vol. 83, pp. 269-272, 2017.

[15] C. Zhai, X. W. Xiang, X. Yu, S. Peng, G. H. Ni, and M. Li, "Sealing performance of flexible gel sealing material of gas drainage borehole," Journal of China University of Mining \& Technology, vol. 42, no. 6, pp. 982-988, 2013.

[16] J. X. Zhang, Y. N. Sun, Z. D. Sun, Z. M. Wang, Y. Y. Zhao, and T. B. Sun, "Analysis of macroscopic mechanical properties and mechanism of coal dust/polymer composite grouting material," Chinese Journal of Rock Mechanics and Engineering, vol. 38, Supplement 1, pp. 2889-2897, 2019.

[17] C. Zhai, X. W. Xiang, Q. L. Zou, X. Yu, and Y. M. Xu, "Influence factors analysis of a flexible gel sealing material for coalbed methane drainage boreholes," Environmental Earth Sciences, vol. 75, no. 5, 2016.

[18] X. X. Chen, R. Bi, and L. Zhang, "Effect of water-to-cement ratio on sulfo-aluminate type cementitious grouting mate- rials," Magazine of Concrete Research, vol. 71, no. 6, pp. 298 308, 2019.

[19] Z. Q. Feng, H. P. Kang, and G. Q. Han, "Polyurethane grouting materials modified by inorganic salts in coal mines," Chinese Journal of Geotechnical Engineering, vol. 35, no. 8, pp. 15591564, 2013.

[20] Z. N. Wang, S. L. Shen, A. N. Zhou, and H. M. Lyu, "Mechanical, flame-retarding, and creep-recovery proprieties of ethylene-propylene-diene monomer enhanced with nanohydroxide for undersea tunnel sealing gasket," Journal of Applied Polymer Science, vol. 138, no. 10, 2021.

[21] Z. N. Wang, S. L. Shen, A. Zhou, and H. M. Lyu, "Experimental investigation of water-swelling characteristics of polymer materials for tunnel sealing gasket," Construction and Building Materials, vol. 256, article 119473, 2020.

[22] Z. N. Wang, S. L. Shen, A. N. Zhou, and Y. S. Xu, "Experimental evaluation of aging characteristics of EPDM as a sealant for undersea shield tunnels," Journal of Materials in Civil Engineering, vol. 32, no. 7, article 4020182, 2020.

[23] J. S. Tan, S. L. Shen, A. Zhou, Z. N. Wang, and H. M. Lyu, "Laboratory evaluation of long-term sealing behaviors of two water-swelling materials for shield tunnel gasket," Construction and Building Materials, vol. 249, p. 118711, 2020.

[24] F. Liu, S. L. Shen, D. W. Hou, A. Arulrajah, and S. Horpibulsuk, "Enhancing behavior of large volume underground concrete structure using expansive agents," Construction and Building Materials, vol. 114, pp. 49-55, 2016.

[25] J. X. Zhang, H. M. Lyu, S. L. Shen, and D. W. Hou, "Investigation of crack control of underground concrete structure with expansive additives," Journal of Materials in Civil Engineering, vol. 33, no. 1, p. 04020420, 2021.

[26] H. C. Du, Y. N. Wang, M. M. He, Z. F. Lin, and Z. Z. Lyu, "Study on the effect of organic retarder on the performance of cement modified emulsified asphalt mastic," Materials Review, vol. 33, no. S2, pp. 254-260, 2019.

[27] L. L. Shui, Z. Sun, H. Yang, X. Yang, Y. Ji, and Q. Luo, "Experimental evidence for a possible dispersion mechanism of polycarboxylate-type superplasticisers," Advances in Cement Research, vol. 28, no. 5, pp. 287-297, 2016.

[28] Y. R. Zhang and X. M. Kong, "Correlation of the dispersing capability of NSF and PCE types of superplasticizer and their impacts on cement hydration with the adsorption in fresh cement pastes," Cement and Concrete Research, vol. 65, no. 3, pp. 1-9, 2015.

[29] J. J. Feng, M. Miao, and P. Y. Yan, "Hydration and expansion properties of shrinkage-compensating composite cementitious materials," Journal of Building Materials, vol. 15, no. 4, pp. 439-445, 2012.

[30] Z. F. Pan, Y. Z. Zhu, D. F. Zhang, N. Chen, Y. C. Yang, and X. N. Cai, "Effect of expansive agents on the workability, crack resistance and durability of shrinkage-compensating concrete with low contents of fibers," Construction and Building Materials, vol. 259, p. 119768, 2020.

[31] W. T. Lan, A. X. Wu, and Y. M. Wang, "Formulation optimization and formation mechanism of condensate expansion and filling composites," Acta Materiae Compositae Sinica, vol. 36, no. 6, pp. 1536-1545, 2019.

[32] R. Y. Bao, Study on the Instability Mechanism of the Sealing Section of the Borehole in Soft Coal Seam and the New Reinforced Seal Technology, [Ph.D. Thesis], Xi'an University of Science \& Technology, China, 2019. 
[33] B. Li, Study on the Mechanism of Microscopic Mechanics of hydrated Calcium silicate (C-S-H) Gel, [Ph.D. Thesis], Harbin Engineering University, China, 2018.

[34] P. Termkhajornkit, R. Barbarulo, and G. Chanvillard, "Microstructurally-designed cement pastes: a mimic strategy to determine the relationships between microstructure and properties at any hydration degree," Cement and Concrete Research, vol. 71, pp. 66-77, 2015.

[35] W. Sekkal, A. Zaoui, M. Benzerzour, and N. Abriak, "Role of porosity on the stiffness and stability of (001) surface of the nanogranular C-S-H gel," Cement and Concrete Research, vol. 87, pp. 45-52, 2016. 